\title{
Sexuality issue in the school environment in a capital city of a West African country
}

\author{
Sosthène Adisso ${ }^{1 *}$, Mukanire N. ${ }^{2}$, Ogoudjobi Mathieu O. ${ }^{1}$, \\ Gnonlonfin N. ${ }^{1}$, Mulongo Mbarambara P. ${ }^{3}$
}

\author{
${ }^{1}$ Faculty of Health Sciences, University of Abomey-Calavi, Cotonou, Benin \\ ${ }^{2}$ Department of Obstetrics and Gynecology, Panzi General Hospital, Bukavu, RDC \\ ${ }^{3}$ Department of Midwifery, ISTM-Bukavu, RDC
}

Received: 02 September 2017

Revised: 10 October 2017

Accepted: 26 October 2017

\section{*Correspondence: \\ Dr. Sosthdne Adissoi, \\ E-mail: noudeli2014@gnail.com}

Copyright: (c) the author(s), publisher and licensee Medip Academy. This is an open-access article distributed under the terms of the Creative Commons Attribution Non-Commercial License, which permits unrestricted non-commercial use, distribution, and reproduction in any medium, provided the original work is properly cited.

\section{ABSTRACT}

Background: Precociousness and abuse of unprotected sexual intercourses among teenagers promote sexually transmitted infections and unwanted pregnancies that often result in illegal induced abortions. The goal of this work is to study the knowledge, attitude and practice of students about sexuality.

Methods: This is a cross-sectional and analytical study that took place from $1^{\text {st }}$ March to $30^{\text {th }}$ May 2015 . All registered secondary students in both secondary schools Behanzin and Toffa 1er from Porto-Novo city are included. We used a multiple choice and open questions.

Results: The survey concerns 1304 students. Among them, 57\% are female and $43 \%$ are male. The students' average age is $18.71 \pm 2.31$ years with extremes of 13 and 25 years. The majority of students in our sample $(66.9 \%)$, the ideal age for first sexual intercourse is between 15 and 19 years with $60.4 \%$ for boys and $65.0 \%$ for girls. In our sample, 6 to 7 students out of 10 have at least one sexual intercourse. Among boys, we estimated 7 to 8 cases out of 10 and among girls 5 to 6 out of 10 cases. On the whole, $44.9 \%$ of students agreed to have sexual intercourse before marriage. Out of 1304 students, 50.0\% have their first sexual intercourse between 15 and 19 years old and $47.2 \%$ of these sexual intercourses were unprotected. Having many sexual partners is more observed among boys. Sexually transmitted diseases are known by students of our sample in the following proportions: HIV/AIDS (93.2\%), Gonorrhoea (44.2\%), Syphilis (21.2\%), Chancroid (6.2\%), Genital trichomoniasis (5.4\%). Out of 433 sexually active girls who were involved in the present study, $165(38.1 \%)$ had at least one unwished pregnancy and 144 which is $87.3 \%$ resulted in induced abortions.

Conclusions: Present study showed that the majority of students are sexually active and most of sexual intercourses are unprotected despite the knowledge about sexually transmitted diseases. This attitude is revealed in a certain rate of unwished pregnancies resulting in a significant proportion of induced abortions.

Keywords: Attitude, Knowledge, Practice, Sexuality, Students

\section{INTRODUCTION}

The taboo of sexuality is a reproductive health concern in Africa, of which our country is Benin. This reflects the lack of communication between parents and children and a threat of sexual behaviour in the ranks of teenagers. According to the demographic and health survey conducted in Benin in 2006 (EDSBIII), $13.12 \%$ of girls and $12.9 \%$ of boys have their first sexual intercourse before the age of 15 years. ${ }^{1}$ 
This is a factor favouring sexually transmitted infections (STIs), unwanted pregnancies most often leading to clandestine interruptions.

In the world almost 100 million of unplanned pregnancies are recorded annually, half of which result in abortions carried out under often dramatic conditions, particularly in countries with restrictive legislation, frequently in young teenage girls. ${ }^{2}$ In Africa, the annual number of abortions has risen from 5.6 million to 6.4 million from 2003 to $2008 .^{3}$ What about among the students of the largest high schools in the capital of Benin?

In Benin, abortion is one of the main causes of maternal death with a $17 \%$ case fatality rate and these abortions occur in $81 \%$ of cases in young people under 19 years of age 4 with daunting, often incurable or fatal complications. To the rank of these complications, there are $30.59 \%$ of cases of haemorrhage, $26.11 \%$ of cases of genital infections, $16.41 \%$ of cases of anaemia, $6.71 \%$ of shock cases, and $3.73 \%$ of uterine perforations 5 and $8 \%$ of cases of infertility. ${ }^{6}$

In addition to unwanted pregnancies, clandestine abortions and their complications, the sexual intercourse of young people, often occasional and unprotected, is also the source of sexually transmitted infections (STIs). A study carried out in Benin in June 2010 revealed that the prevalence of STIs is significantly higher among urban youth than among young people in rural areas $(2.3 \%$ versus $0.3 \%$ ). The same survey showed that students and students are the most affected. ${ }^{7}$

The most visible impact of unwanted pregnancy lies in the psychosocial field because it contributes to a loss of self-esteem, dropout, rejection by the family, destruction of life projects and the maintenance of the vicious circle of poverty. The aim is to study the knowledge, attitudes and practices of students in sexuality matter.

\section{METHODS}

Present study included Béhanzin secondary school and Toffa 1er secondary school; these two are the oldest public schools in Porto-Novo (the political capital city of Benin, a West African country).

This is a cross-sectional study with a descriptive and analytical purpose, carried out from 1 March to 30 May 2015. The study population consists of students: girls and boys registered in both schools during the 2014-2015 academic year.

We conducted a survey using pre-established questions. The variables studied relate to the specific knowledge about sexually transmitted diseases during sexual intercourse when girls are in the period of childbirth. As for attitudes towards sexuality, we have studied the ideal age for having first sexual intercourse, for having first child and students' opinion on illegal induced abortions.
Their sexual practices were explored using questions about the age of student during the first intercourse, reasons, frequency and sexual intercourse planning, the number of sexual partners, the unwanted pregnancy occurrence and its outcome.

We carried out an exhaustive census of all girls and boys in the second cycle of different secondary schools $\left(11^{\text {th }}\right.$, $12^{\text {th }}$ and $13^{\text {th }}$ classes $)$. Students were asked multiple choice and open questions after pre-testing and clear explanations, all this out of school hours. Confidentiality was respected. The files were anonymously filled and picked up on the spot. The data were processed using SPSS 20.0 and Epi info 6 software.

\section{RESULTS}

\section{Student profile}

During the present study, 1304 students were surveyed. Among them 556 were boys $(42.6 \%)$ and 748 were girls (57.4\%). The average age of students in the present study is $18.71 \pm 2.31$ years.

\section{Knowledge and attitudes of students about sexuality}

Table 1 shows the distribution of students according to their sexuality knowledge.

Table 1: Students distribution according to their sexuality knowledge.

\begin{tabular}{|llll|}
\hline $\begin{array}{l}\text { Knowledge about } \\
\text { childbirth period }\end{array}$ & 783 & Yes & Total \\
\hline $\begin{array}{l}\text { Knowledge about } \\
\text { sexually transmitted } \\
\text { diseases }\end{array}$ & 12 & $129 \%)$ & 1304 \\
$(0.9 \%)$ & $(99.1 \%)$ & $(100.0 \%)$ \\
\hline
\end{tabular}

In the present study, 783 students out of 1304, which is $60.0 \%$, do not know about the childbirth period. Sexually transmitted diseases are known to 1292 students out of 1304 cases, which is $99.1 \%$. The best known sexually transmitted diseases are HIV/AIDS (93.2\%), Gonorrhea (44.2\%) and Syphilis (21.2\%).

The ideal age to have a first intercourse mentioned is between 15 to 19 years for 872 students out of the 1304 , which represent $66.9 \%$ of the cases. The ideal age to have a first child $\geq 25$ years for 394 boys and 483 girls.

Induced abortion is recognized as bad outcome of pregnancy by the majority, 1120 students out of 1304 , which is $85.9 \%$.

\section{Student practices in sexuality}

Table 2 shows the students distribution according to their sexual practices. 
Table 2: Students distribution according to their sexual practices.

\begin{tabular}{|llll|}
\hline Sexually active & 463 & 841 & Total \\
students & $(35.5 \%)$ & $(64.5 \%)$ & $(100.0 \%)$ \\
\hline Planned sexual & 443 & 398 & 841 \\
intercourse & $(52.7 \%)$ & $(47.3 \%)$ & $(100.0 \%)$ \\
\hline Pregnancy & 244 & 199 & 443 \\
incidence & $(55.1 \%)$. & $(45.9 \%)$ & $(100.0 \%)$ \\
\hline Wished & 165 & 34 & 199 \\
pregnancies & $(82.9 \%)$ & $(17.1 \%)$ & $(100.0 \%)$ \\
Induced abortion & 21 & 144 & 165 \\
& $(12.7 \%)$ & $(87.3 \%)$ & $(100.0 \%)$ \\
\hline
\end{tabular}

In the present study 841 students out of 1304, which is $64.5 \%$ have already had at least one sexual intercourse. The minimum age at first intercourse is 10 years and the maximum age is 23 years. The average age is $17.18 \pm 1.73$ years for boys and $16.19 \pm 2.27$ years for girls. The proportion of girls who have sexual intercourse at the age of 15 is higher than that of boys ( $84.7 \%$ versus $69.8 \%$ ). The reasons for having sex are many and the best mentioned are in the following proportions: curiosity, 452 out of $841(53.7 \%)$; Sexual desire, 186 out of 841 which is $22.6 \%$ of cases; pleasure 80 out of 841 which is $9.5 \%$. These intercourses occur 1 to 4 times per month by 675 out of 841 students, which is $80.3 \%$; 5 to 8 times a month by 74 students out of 841 , which is $8.8 \%$ and more than 9 times a month by 39 students, which is $4.7 \%$.

Among sexually active students, 437 out of 841 , which is $51.96 \%$ of cases had at least 2 sexual partners. The majority of students have at least 2 partners. Among 841 sexually active students, 398, which is $47.3 \%$ had planned intercourse while cases of unplanned intercourse were 443 which represent $52.7 \%$. In the present study, 199 pregnancies cases were reported to 433 sexually active girls which is $45.9 \%$. Among these pregnancies, 165 were unwanted which is $82.9 \%$. Cases of induced abortion occurred to 144 girls out of 165 who became pregnant which is $87.3 \%$.

\section{DISCUSSION}

\section{Student knowledge and attitudes about sexuality}

A good knowledge about sexuality would be an advantage for every teenager in our sphere. Compared to the results of the EPICE survey carried out in Paris in 2010, we can conclude that HIV/AIDS is the best known STI, probably because of many awareness campaigns. ${ }^{8}$

For the majority of students in our sample $(66.9 \%)$, the ideal age for first sexual intercourse is between 15 and 19 years $(60.4 \%$ versus $65.0 \%)$. Boys were more likely to have their first child after 25 years than girls $(70.9 \%$ versus $64.6 \%, \mathrm{p}=0.000$ ). Approximately 4 to 5 out of 10 students had intercourse before marriage. Romels et al in the Philippines reported 1 to 3 out of 10 students in their study. ${ }^{9}$

\section{Student practices in sexuality}

Half of our sample had sexual intercourse between 15 and 19 years, while UNICEF in Congo in 2007 and ORS in the West Indies in 2012 found different age groups compared to the present, which are respectively 12 and 15 years, 15 and 16 years. ${ }^{10,11}$

The average age for boys at first intercourse is 17.18 years and for girls is 16.19 years. These ages are close to those found in an EPICE survey carried out in Paris in 2009-2010, which was 17.3 years for girls and 16.8 years for boys. ${ }^{8}$

On the other hand, a study carried out in France in 2001 found an age close to 17 years for both sexes (17 years and 3 months for boys and 17 years and 6 months for girls) and that carried out by the EDSB -IV in Benin in 2011-2012 had found 15 years for both sexes. ${ }^{12,13}$ It can say that the first sexual intercourse seems precocious and this regardless of the country. In the present sample, sexual intercourses are not planned by nearly half of the students. This rate is 1.5 times lower than that reported by a study carried out in Switzerland in 2009 by the federal commission for childhood and youth. ${ }^{14}$

Among the surveyed teenagers, 6 to 7 students out of 10 have at least 2 partners. This same observation was made by the 1993 ACSF survey and a study carried out by the DFS / MINI SANTE in Burkina Faso in 2012 but with lower proportions, which were respectively $25 \%$ and $21 \%$ ( 2 to 3 students out of 10). ${ }^{15,16}$ In this study, $82.9 \%$ had an unwished pregnancy. This value is twice as high as that reported by the KABP study in the West Indies in 2012, which was $35 \% .^{12}$

The lack of knowledge about contraceptive methods, complications of illegal pregnancy interruptions and having many partners may all contribute to the occurrence of unwished pregnancies.

Out of 165 girls who were unwillingly pregnant, 144 girls which is $87.3 \%$ had an induced abortion. According to a study carried out in France in 2004, the number of IVG/abortions among teenagers' girls in relation to 100 conceptions was $53.3 \%$ in Seine Saint-Denis and $61.2 \%$ in metropolitan France. ${ }^{17}$ These rates are twice as high as those found by the KABP survey in the West Indies in 2012 which was $35 \%$. We can say that the prevalence of willful pregnancy interruptions differs from one country to another and depends mainly on the prevalence of unwished pregnancies.

\section{CONCLUSION}

This study leads us to conclude that sexual activities are rather precocious by girls than boys, which explains 
unwished pregnancies ending in most cases by induced illegal abortions. Integration of educational activities on sexuality in the school in Africans countries like Benin constitute a way to prevent those practices among students.

\section{ACKNOWLEDGMENTS}

Authors would like to thank Students for their availability in involving in this study.

Funding: No funding sources Conflict of interest: None declared

Ethical approval: The study was approved by the Institutional Ethics Committee

\section{REFERENCES}

1. INSAE, PNLS, UNICEF, USAID, UNFPA. Demographic and Health Survey (EDBS-III), Bénin 2006. Cotonou: National Institute of Statistics and Economic Analysis (INSAE); 2007:244-57.

2. Serfaty D, d'Arcangues C, Audebeth A, Belaish J. Contraception in practice. 4th edition. Elsevier Masson SAS; 2011:11-20,263.

3. Sedgh G, Singh S, Shah IH, Åhman E, Henshaw SK, Bankole A. Induced abortion: incidence and trends worldwide from 1995 to 2008. The Lancet. 2012;379(9816):625-32.

4. Goyaux N, Alihonou E, Diadhiou F, Leke R, Fernand Thonneau P. Complications of induced abortion and miscarriage in three African countries: a hospital based study among WHO collaborating centers. Scandinavian Obstetric Record. 2001;80(6):568-73.

5. Lombat DSA. Post-abortion care at Cotonou lagoon maternity hospital about 485 cases of abortions recorded at Cotonou Lagoon maternity hospital. Cotonou: Abomey-Calavi University FSS; 2000: $N^{\circ} 906$

6. Alihonou E, Carre N, Capochichi V, Thonneau P. Contraceptive continuation and its déterminants in Benin. Contracept. 1997;55(2):97-101.

7. Minister of Public Health UNFPA. Multisectoral national strategy for sexual and reproductive health of adolescents and youth in Benin 2010-2020. Mother and Child Health Directorate. 2010:40.

8. Fenton KA, Lowndes CM. Recent trends in the epidemiology of sexually transmitted infections in the European Union. Sexually Transmitt Infect. 2004;80(4):255-263.

9. Romels SL, Theocharis RT, Strack. Correlate of sexual abstinence among urban university students in the Philippines. Int Fam Plann Perspect. 1997;23:168-72.

10. UNICEF. Study on Adolescents' Knowledge, Attitudes, Practices and Behaviors in Sexuality, Procreation and VIH/SIDA Brazzaville. Study Report. 2007:17.

11. ORS (Regional Health Observatory). The knowledge, attitudes, beliefs and behaviors regarding the risks associated with sexual behavior. 2012 KABP Meeting Survey: First Results. 2014:7-9.

12. Bajos N, Durand S. Sexual and Reproductive Behaviors of Adolescents Comparison between Developed Countries. 2001 November; Occasional Report No. 9.

13. INSAE. Ministry of Development, Economic Analysis and Foresight of Benin. Demographic and Health Survey (EDSB-IV) 2011-2012. 2013:245.

14. DF (Federal Department of the Interior). The sexuality of young people over time Evolution, influences and perspectives. Swiss Report. 2009;29.

15. Bajos N, Spira A, Ducot B, Messiah A. Analysis of sexual behaviour in France (ACSF): A comparison between two modes of investigation: Telephone survey and face-to-face survey. Aids. 1992.

16. UNFPA, DSF/MINI SANTE. Knowledge attitudes and practices of the populations of Burkina-Faso in the field of reproductive health. AFRIC SANTE. 2013:93.

17. Embersin C. Prevention of unwanted pregnancies in three departments: Rhône, Seine-Saint-Denis, Somme. Paris, FNORS;2004.

Cite this article as: Adisso S, Mukanire N, Ogoudjobi OM, Gnonlonfin N, Mulongo MP. Sexuality issue in the school environment in a capital city of a West African country. Int J Reprod Contracept Obstet Gynecol 2017;6:5188-91. 